\title{
NGHIÊN CỬU TÁC NHÂN GÂY BỆNH PHÁT SÁNG DO VI KHUẪN VIBRIO HARVEYI TRÊN ẤU TRÙNG VÀ GIỐNG CUA XANH (SCYLLA SERRATA) TRONG TRẠI SẢN XUẤT GIỐNG
}

\author{
Trần Thế Mưu, Vũ Văn Sáng* \\ Trung tâm Quốc gia Giống Hải sản miền Bắc-Viện Nghiên cưu Nuôi trồng Thủy sản I \\ "E-mail: vuvansangts50@gmail.com \\ Ngày nhận bài: 21-4-2015
}

\begin{abstract}
TÓM TÄT: Bệnh phát sáng là một bệnh nguy hiểm và phổ biến trong các trại sản xuất cua giống (Scylla serrata) ở miền Bắc. Tỷ lệ chết gây ra do bệnh này có thể lên tới 50 - 100\% sau 2 - 3 ngày nhiễm bệnh nếu không có biện pháp chũa trị kịp thời. Bằng phuoong pháp định danh vi khuẩn (phuoong pháp thư phản úng sinh hoá và phuoong pháp đọc và so sánh trình tự gen $16 S$ rDNA) và gây cảm nhiễm nhân tạo, chúng tôi đã xác định tác nhân gây bệnh phát sáng trên ấu trùng và cua giống là vi khuẩn Vibrio harveyi và phuoong pháp trị bệnh hiệu quả thông qua hai buớc: Dùng hoá chất Pemanganat kali, Chlorine, Formalin khư trùng nước, cua mẹ, thức ăn (artemia) và dụng cu chuyên dụng sau đó dùng một trong 3 loại kháng sinh Neomycin, Erythromycin hoạc Doxycyclin với nồng độ $2 \mathrm{ppm} /$ ngày trong 3 ngày đầu liên tiếp ở mỗi giai đoạn (Zoea, Megalop và cua giống) để phòng bệnh và 3 ppm/ngày trong 3 ngày liên tiếp kể tù khi ấu trùng nhiễm bệnh để trị bệnh.
\end{abstract}

Tù khóa: Áu trùng và giống cua xanh, Scylla serrata, bệnh phát sáng, vi khuẩn.

\section{ĐẠT VẤN ĐỀ}

Cua xanh là một trong những đối tượng nuôi thuỷ sản có giá trị kinh tế ở Việt Nam. Kỹ thuật nuôi cua đơn giản, tốc độ sinh trưởng nhanh và giá cua thương phẩm thị trường tương đối ổn định (từ $120.000-180.000$ đồng/ $/ \mathrm{kg}$ ). Hàng năm ước tính cần khoảng 1 tỷ con giống cua để thả nuôi trên hàng ngàn hecta diện tích ao đầm, nhưng hiện nay con giống khai thác từ tự nhiên chỉ đáp ứng được khoảng $10-20 \%$ so với nhu cầu cua giống cho nuôi thương phẩm [1]. Việc nghiên cứu sản xuất giống cua xanh thành công đã góp phần thúc đẩy nghề nuôi cua phát triển. Tuy vậy, trước tình hình thực tiễn các trại sản xuất giống cua biển đang gặp một số vấn đề về dịch bệnh làm ấu trùng và cua giống chết hàng loạt, tỷ lệ sống trung bình từ Zoea 1 đến cua giống rất thấp chỉ đạt dưới $4 \%$ [2]. Bệnh cua không những là nguyên nhân làm giảm tỷ lệ sống, giảm sản lượng mà còn làm giảm chất lượng ấu trùng và con giống. Cho đến nay, đã phát hiện ra được bệnh ấu trùng cua do nhiều tác nhân gây ra như vi khuẩn, nấm, ký sinh trùng và vi rút [2]. Trong đó, bệnh phát sáng ở âu trùng và cua giống là một trong những bệnh đặc biệt nghiêm trọng. Bệnh xảy ra ở nhiều trại sản xuất giống cua tại Hải Phòng, Nam Định và nhiều địa phương khác làm chêt hàng loạt và gây thiệt hại lớn cho các trại sản xuất giống cua biển. Cho đến nay, các nghiên cứu về bệnh phát sáng ở ấu trùng và cua giống còn rất hạn chế. Vì vậy, việc nghiên cứu tác nhân gây bệnh phát sáng do vi khuẩn Vibrio trên âu trùng và giống cua xanh là hết sức cần thiết, góp phần không nhỏ vào sự phát triển của nghề nuôi cua biển ở Việt Nam.

\section{PHƯƠNG PHÁP NGHIÊN CÚU}

Để xác định chính xác tác nhân gây bệnh phát sáng ở ấu trùng và cua giống, chúng tôi 
dùng phương pháp phân lập và định danh vi khuẩn theo các tác giả Musselius (1993), Ferich (1993) và Bergey (2001) bằng phương pháp phân tử $16 \mathrm{~s}$ rDNA và phương pháp đọc và so sánh trình tự gen $16 \mathrm{~S}$ rDNA) sau đó dùng chủng vi khuẩn phân lập được trên mẫu bệnh để gây cảm nhiễm nhân tạo.

Vật liệu thí nghiệm là ấu trùng và cua giống chúng tôi thu tại các trại sản xuất giống ở miền Bắc và thu 30 mẫu cho mỗi loại.

Thí nghiệm được thực hiện tại Trạm Nghiên cứu Nuôi trồng thủy sản nước lợ thuộc Trung tâm Quốc gia giống Hải sản miển Bắc, Viện Nghiên cứu Nuôi trồng thủy sản 1 .

Phương pháp đọc và so sánh trình tự gen 16S r DNA chi tiết như sau:

Tách chiết DNA tổng số

Ly tâm thu dịch tế bào ở tốc độ 10.000 rpm trong 5 phút, rồi thu cặn, hoà vào trong $567 \mu 1$ (1 TE $(10: 1)$ để trên đá và votex, tiếp đó thêm vào $30 \mu \mathrm{l}(1 \mathrm{SDS} 10 \%)$ trộn 3 lần, rồi thêm vào $3 \mu \mathrm{l}$ (1 Protease K $(2 \mathrm{mg} / \mathrm{ml})$, tiếp đó ủ ở $37^{\circ} \mathrm{C}$ trong 1 giờ, rồi thêm $180 \mu \mathrm{l}(1 \mathrm{NaCl} 5 \mathrm{M}$, ủ ở $56^{\circ} \mathrm{C}$ trong 10 phút), thêm $1 \mathrm{~V}$ Chloroform: Isoamyl (24:1), tiếp đó ly tâm $12.000 \mathrm{rpm}$ trong 10 phút, lặp lại bước trên 1 lần nữa, rồi thu lấy dịch trong, bồ sung 1/10 V Sodium acetate $5 \mathrm{M}$ và $2,5 \mathrm{~V}$ Ethanol $100 \%$, giữ ở $-25^{\circ} \mathrm{C}$ trong 2 giờ, sau đó ly tâm $12.000 \mathrm{rpm}$ trong 20 phút để thu tủa, thu tủa và hong khô, thêm $400 \mu \mathrm{l}$ (1 TE - ARNase, ủ ở $37^{0} \mathrm{C}$ trong 1 giờ, cuối cùng kiểm tra DNA tổng số bằng điện di Agarose.

Tối ưu hoá điều kiện chạy PCR nhân gen 16S rDNA

Thành phần phản ứng chạy PCR nhân gen 16S rDNA (bảng 1).

Bảng 1. Thành phần phản ứng nhân gen $16 \mathrm{~S}$ rDNA của Vibrio sp.

\begin{tabular}{|c|c|c|}
\hline Thành phần & Nồng độ & Lượng hút \\
\hline PCR buffer & $10 X$ & $2 \mu \mathrm{l}$ \\
\hline Taq polymerase & $5 \mathrm{u} / \mu \mathrm{l}$ & $0,3 \mu \mathrm{l}$ \\
\hline dNTPs & $2,5 \mathrm{mM}$ & $1,5 \mu \mathrm{l}$ \\
\hline DNA template & $50 \mathrm{ng} / \mu \mathrm{l}$ & $2 \mu l$ \\
\hline Mồi 5 F & $10 \mu \mathrm{M}$ & $1 \mu \mathrm{l}$ \\
\hline Mồi 1525 R & $10 \mu \mathrm{M}$ & $1 \mu \mathrm{l}$ \\
\hline Nước cất chạy PCR & & $12,2 \mu \mathrm{l}$ \\
\hline
\end{tabular}

Phuoong pháp xác định mật độ vi khuẩn: Bằng phương pháp so màu dùng bộ ống chuẩn Mc - Faland's.

Để đưa ra phương pháp phòng và trị bệnh phát sáng chúng tôi bố trí thí nghiệm theo sơ đồ khối ngẩu nhiên trong bể kính thể tích 10 lít, mật độ thả ấu trùng cua ban đầu là 10 con/lít. Ba loại kháng sinh phổ biến trên thị trường đó là Erythromycin, Doxycyclin, Neomycin được lựa chọn thử nghiệm với nồng độ và thời gian tác dụng khác nhau.

\section{Phuoong pháp phân tích số liệu}

Sử dụng chương trình DNA STAR để xử lý trình tự và vẽ cây phát sinh loài.

\section{KẾT QUẢ VÀ THẢO LUẬN}

\section{Kết quả định danh vi khuẩn trên mẫu bệnh phát sáng}

\section{Nuôi cấy và phân lập vi khuẩn}

Bằng phương pháp nuôi cấy và phân lập vi khuẩn trên môi trường TCBS, chúng tôi đã xác định được 4 chủng vi khuẩn Vibrio (V1, V2, V3 và V4) hiện diện trên mẫu bệnh ấu trùng, cua giống phát sáng với tỷ lệ xuất hiện tương ứng là $0,00-18,8 \% ; 75,0-100 \% ; 11,1-25,0 \%$ và $0,00-12,5 \%$.

Như vậy, chủng vi khuẩn V2 được coi là chủng vi khuẩn chiếm ưu thế trong mẫu bệnh phát sáng.

\section{Định danh vi khuẩn trong mẫu bệnh phát sáng}

Kết quả thử phản ứng sinh hoá: Bằng phương pháp thông dụng này chúng tôi đã xác định được chủng V1 là $V$. ordalii, chủng V2 là $V$. harveyi, chủng $\mathrm{V} 3$ là $V$. alginolyticus và chủng V4 là $V$. parahaemolyticus.

\section{Kết quả đọc và so sánh trình tụ gen 16s rDNA}

Căn cứ vào kết quả trên, chúng tôi xác định được chủng vi khuẩn V2 là chủng vi khuẩn chiếm ưu thế trong các mẫu bệnh phát sáng. Do vậy, chúng tôi chỉ định danh chủng vi khuẩn bằng kỹ thuật sinh học phân tử.

Bằng phương pháp đọc và so sánh trình tự gen 16s rDNA tại Viện Công nghệ Sinh học chủng vi khuẩn cần định danh V2, chúng tôi thu được kết quả: 
Đã nhân được gen 16s rDNA của loài Vibrio sp. với kích thước tương ứng khoảng $1,4 \mathrm{~kb}$. Tuy nhiên, sản phẩm này chưa đặc hiệu, do vậy phải tiến hành thôi gen và tinh sạch sản phẩm PCR trước khi đọc trình tự. Kết quả sản phẩm PCR, thôi gen và tinh sạch được thể hiện ở hình 1 và hình 2 .

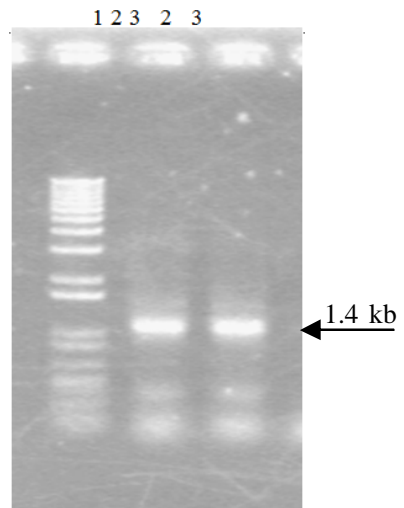

Hình 1. Kết quả nhân gen $16 \mathrm{~S}$ rDNA của loài Vibrio sp. từ bệnh phát sáng

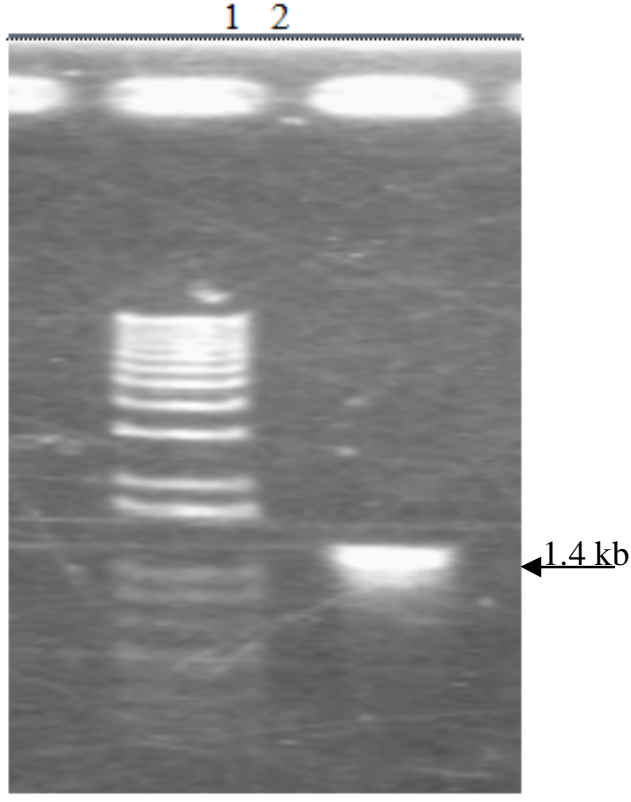

Hình 2. Kết quả tinh sạch gen $16 \mathrm{~S}$ rDNA của loài Vibrio $\mathrm{sp}$. từ bệnh phát sáng

Đọc trình tụ gen 16s rDNA của loài Vibrio sp. (889bp)

GAACGCTGGCGGCAGGCCTAACACATGCAAGTCGAGCGGAAACGAGTTATCTGAACCT TCGGGGGACGATAACGGCGTCGAGCGGCGGACGGGTGAGTAATGCCTAGGAAATTGCC CTGATGTGGGGGATAACCATTGGAAACGATGGCTAATACCGCATAATGCCTACGGGTCA AAGAGGGGGACCTTCGGGCCTCTCGCGTCAGGATATGCCTAGGTGGGATTAGCTAGTT GGTGAGGTAATGGCTCACCAAGGCGACGATCCCTAGCTGGTCTGAGAGGATGATCAGC CACACTGGAACTGAGACACGGTCCAGACTCCTACGGGAGGCAGCAGTGGGGAATATT GCACAATGGGCGCAAGCCTGATGCAGCCATGCCGCGTGTGTGAAGAAGGCCTTCGGGT TGTAAAGCACTTTCAGTCGTGAGGAAGGTAGTGTAGTTAATAGCTGCATTATTTGACGT TAGCGACAGAAGAAGCACCGGCTAACTCCGTGCCAGCAGCCGCGGTAATACGGAGGG TGCGAGCGTTAATCGGAATTACTGGGCGTAAAGCGCATGCAGGTGGTTTGTTAACTCAG ATGTGAAAGCCCGGGGCTCAACCTCGGAATAGCATTTGAAACTGGCAGACTAGAGTAC TGTAGAGGGGGGTAGAATTTCAGGTGTAGCGGTGAAATGCGTAGAGATCTGAAGGAAT ACCGGTGGCGAAGGCGGCCCCCTGGACAGATACTGACACTCAGATGCGAAAGCGTGG GGAGCAAACAGGATTAGATACCCTGGTAGTCCACGCCGTAAACGATGTCTACTTGGAG GTTGTGGCCTTGAGCCGTGGCTTTCGGAGCTAACGCGTTAAGTAGACCGCCTGGGGAG TACGGTCGCAAGATTAAAA

Sử dụng chương trình DNA STAR để xử lý trình tự, kết quả cho thấy loài Vibrio sp. được phân lập từ mẫu bệnh phát sáng tự nhiên và mẫu bệnh phát sáng nhân tạo do gây cảm nhiễm (Vibrio sp.) đã được so sánh với các loài Vibrio khác có trong ngân hàng gen (GENBANK) cho thấy: chủng Vibrio sp. (V2) có tỷ lệ phần trăm tương đồng cao nhất so với loài $V$. harveyi là $99,7 \%$ và khoảng cách di truyền tương ứng là 0,2 ; tiếp đó là loài $V$. carchiariae có tỷ lệ phần trăm tương đồng là $99,8 \%$ và khoảng cách di truyền là 0,3 . Tiếp đến là hai loài $V$. alginolyticus và $V$. parahaemolyticus có tỷ lệ phần trăm tương đồng là 99,3\% và khoảng cách di truyền là 0,6 và 0,7 tương ứng. 
Qua đó, chúng tôi có thể khẳng định chủng vi khuẩn V2 (Vibrio sp.) được phân lập từ mâ̂u bệnh phát sáng tại Hải Phòng và Nam Định là loài Vibrio harveyi.

Bảng 2. Bảng phần trăm tương đồng và khoảng cách di truyền của các chủng Vibrio với chủng Vibrio sp. (V2)

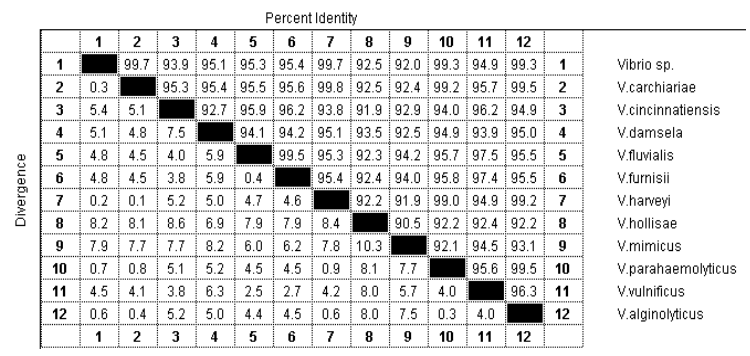

Ghi chú: Divergence: Khoảng cách di truyền, Percent Identity: tỷ lẹ phần trăm (\%) tuong dồng.

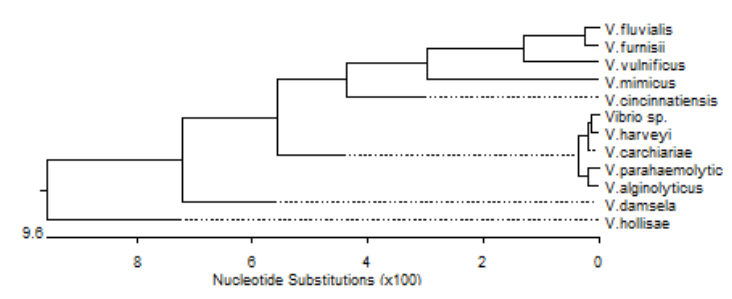

Hình 3. Cây phát sinh chủng loại của các loài Vibrio

Kết quả gây cảm nhiễm và định danh lại vi khuân từ mẫu bệnh nhân tạo

Gây cảm nhiễm vi khuẩn với ấu trùng, cua giống

Kết quả gây cảm nhiễm ấu trùng và cua giống với vi khuẩn Vibrio harveyi cho thấy: Trong các giai đoạn phát triển của ấu trùng (từ Zoea đến Megalop và cua giống) thì giai đoạn Zoea là giai đoạn rất dễ mẫn cảm nhất với $V$. harveyi (đặc biệt Zoea 2). Với mật độ vi khuẩn $V$. harveyi đạt $6,0 \times 10^{3} \mathrm{CFU} / \mathrm{ml}$, ấu trùng Zoea đến 48 giờ đã xuất hiện bệnh phát sáng. Trong khi đó, ở các lô thí nghiệm cảm nhiễm Megalop và cua với vi khuẩn $V$. harveyi, thì ấu trùng Megalop phát sáng sau 72 giờ với mật độ vi khuẩn đạt trên mức $1,0 \times$ $10^{5} \mathrm{CFU} / \mathrm{ml}$, cua giống phát sáng sau 72 giờ với mật độ vi khuẩn đạt trên mức $1,0 \times$ $10^{7} \mathrm{CFU} / \mathrm{ml}$.
Kết quả gây cảm nhiễm ấu trùng và cua giống với 3 chủng vi khuẩn $(V$. ordalii, $V$. alginolyticus và $V$. parahaemolyticus) đã xác định được cả 3 chủng $V$. parahaemolyticus, $V$. ordalii và $V$. alginolyticus không phải là tác nhân gây bệnh phát sáng trực tiêp. Rất có thể các chủng vi khuẩn này sẽ kết hợp với chủng $V$. harveyi làm bệnh phát sáng trở nên trầm trọng và khó chữa trị.

\section{Phân lập và định danh lại vi khuẩn tù̀ mẫu bệnh phát sáng nhân tạo}

Trong quá trình thí nghiệm gây cảm nhiễm nhân tạo, chúng tôi tiến hành thu mẫu bệnh phẩm bệnh phát sáng và tiến hành định danh lại vi khuẩn bằng cả hai phương pháp (thử phản ứng sinh hoá và đọc và so sánh trình tự gen $16 \mathrm{~S}$ rDNA). Kết quả đã thu được trong các mẫu phát sáng nhân tạo là chủng vi khuẩn $V$. harveyi, đó cũng là chủng vi khuẩn mà trước đó chúng tôi dùng để gây cảm nhiễm.

\section{Kết quả xác định tác nhân gây bệnh phát sáng trên ấu trùng và cua giống}

Qua các kết quả định danh vi khuẩn và kết quả thí nghiệm gây cảm nhiễm nhân tạo trên ấu trùng và cua giống ở trên, chúng tôi đã xác định được bệnh phát sáng ở ấu trùng cua xanh là do loài vi khuẩn Vibrio harveyi.

\section{Phòng và trị bệnh}

Trong quá trình sản xuất cua giống, biện pháp phòng bệnh là chính và chữa bệnh phải kịp thời, ngoài việc phòng bệnh từ xa bằng cách dùng các hoá chất xử lý nước, thức ăn, cua bố mẹ, dụng cụ nuôi thì việc dùng kháng sinh để phòng khuẩn trong quá trình nuôi là rất cần thiết.

Để phòng và trị bệnh phát sáng chúng ta cần quan tâm đến việc xử lý nước và dụng cụ bằng các chất diệt khuẩn mạnh như Kali Pemanganat (nồng độ 3 - 5 ppm trong 24 giờ), Chlorine (nồng độ 50 - 60 ppm trong 1 tuần) và Formalin (nồng độ 20 - 30 ppm trong 24 giờ). Trong quá trình ương nuôi cân kết hợp với việc phòng bệnh này bằng việc chọn 1 trong 3 loại kháng sinh (Erythromycin, Doxycyclin và Neomycin) với nồng độ $2 \mathrm{ppm} / \mathrm{ngày}$ và sử dụng trong 3 ngày đầu liên tiếp ở mỗi giai đoạn phát triển của ấu trùng. 
Kết quả phòng bệnh phát sáng trên ấu trùng và cua giống là dùng một trong 3 loại kháng sinh (Erythromycin, Doxycyclin và Neomycin) với nồng độ $2 \mathrm{ppm} /$ ngày trong 3 ngày đầu liên tiếp ở mỗi giai đoạn (Zoea, Megalop và cua giống).

Kết quả trị bệnh bằng một trong 3 loại kháng sinh (Erythromycin, Doxycyclin và Neomycin) với nồng độ $3 \mathrm{ppm} /$ ngày trong 3 ngày liên tiếp kể từ khi ấu trùng nhiễm bệnh.

\section{KẾT LUẬN}

Kết quả nghiên cứu về bệnh phát sáng trên ấu trùng và cua giống, chúng tôi đã xác định được tác nhân gây bệnh là vi khuẩn $V$. harveyi, vi khuẩn này thường có mặt trong nước biển, nước lợ và thậm chí trên cua mẹ vùng biển Hải Phòng.

Đặc điểm của loài vi khuẩn này có dạng hình que, bắt màu Gram âm, khuẩn lạc có dạng tròn, lồi màu xanh mọc trên môi trường chọn lọc TCBS sau 24 giờ nuôi cấy ở nhiệt độ 26 $28^{0} \mathrm{C}$.

Khi vi khuẩn Vibrio harveyi đủ số lượng và độc lực sẽ tấn công ấu trùng đặc biệt là những cá thể ấu trùng yếu trong bể ương sẽ dẫn đến phát sáng.

Bệnh phát sáng được xử lý bằng việc chọn 1 trong 3 loại kháng sinh (Erythromycin, Doxycyclin và Neomycin) với nồng độ 3 ppm/ngày trong 3 ngày liên tiếp.

\section{TÀI LIỆU THAM KHẢO}

1. Baticados, M. C. L., and Pitogo, C. L., 1990. Chlorination of seawater used for shrimp culture. The Israeli Journal of Aquaculture-Bamidgeh, 42(4): 128-130.

2. Baticados, C. L., 1988. Control of luminous bacterial infection in prawn hatcheries. SEAFDEC Asian Aquaculture (Philippines). No 1, 2-4.

3. Hoàng Đức Đạt, 2000. Kỹ thuật nuôi cua biển. Nxb. Nông nghiệp. Tp. Hồ Chí Minh.

4. Lavilla-Pitogo, C. R., Leobert, D., \& la Peña, D., 2004. Diseases in Farmed Mud Crabs Scylla Spp: Diagnosis, Prevention, and Control. Aquaculture Department, Southeast Asian Fisheries Development Center.

5. Linda L. and Mccarter, 1998. Controls Opacity of Vibrio parahaemolyticus. http://linda-mccarter@uiowa.edu.

6. Nguyễn Co Thạch, 2000. Nghiên cứu sinh sản nhân tạo cua biển loài cua Scylla serrata (Forskal, 1775). Báo cáo tổng kết đề tài cấp Bộ. Bộ Nông nghiệp và Phát triển Nông thôn. 120 tr.

7. Pitogo, C. L., 1988. Isolation and identification of luminous bacteria causing mortalities in Penaeus monodon hatcheries in Panay [Philippines]. SEAFDEC Asian Aquaculture (Philippines). No 1, 11 -13.

8. http:// webmaster@watson.wustl.edu.

9. West P.A., 1996. Numerical taxonomi of Vibriosis isolated from aquatic environment. Int.J syst. Bacteriol.36: 531 - 543.

\title{
STUDY ON PATHOGEN OF LUMINOUS DISEASE VIBRIO HARVEYI ON LARVAE AND JUVENILE OF MUD CRAB (SCYLLA SERRATA) IN HATCHERY
}

\author{
Tran The Muu, Vu Van Sang \\ Research Institute for Aquaculture Number 1
}

\begin{abstract}
Luminous disease is known as the most popularly dangerous disease in the hatcheries of mud crab (Scylla serrata) in northern provinces. Without any treatment, the mortality caused by this disease may reach 50 - 100\% after 2 - 3 days infected. In this study, Vibrio harveyi
\end{abstract}


has been identified as the main pathogen which causes the disease in larvae and juvenile of mud crab by using method for bacteria identification (bio-chemical reaction and comparision of the gene $16 S$ rDNA) as well as artificial disease infection. In addition, we have developed successful prevention and treatment for this disease as follows: potasium permanganate, chlorine, formaline used for treatment of water, crab spawners, living food (artemia), utensils and equipment, after that one of the three different kinds of antibiotics can be used: Neomycine, Erythromycine or Doxycyclin. For prevention, the dose of 2 ppm/day can be applied for 3 consecutive beginning days of each development stage (Zoea, Megalope and juvenile), and 3 ppm/day can be applied for 3 consecutive days for disease treatment.

Keywords: Larvae and juvenile of mud crab, Scylla serrata, luminous disease, bacteria. 